\title{
Excessive plasma dopamine increase at rest and during exercise after long-term beta-adrenoreceptor blockade in hypertensive patients
}

\author{
I-W FRANZ, F W LOHMANN, G KOCH \\ From the Department of Sports Medicine, Free University; Department of Medicine, Neukölln Hospital; \\ Department of Physiology, Free University, Berlin
}

SUMMARY The effect of four weeks and 15 months of treatment with the cardioselective beta-receptor antagonist metoprolol on blood pressures, plasma noradrenaline, adrenaline, and dopamine at rest, during submaximal steady state and near maximal exercise, as well as five minutes after exercise, was studied in seven moderately hypertensive men aged 25 to 51 years.

Four weeks of treatment resulted in significantly lower heart rates and blood pressures at rest, during, and after exercise; no further significant changes were observed after 15 months of continuous treatment.

The exercise-induced increase in plasma noradrenaline and adrenaline tended to be more pronounced after treatment with metoprolol with virtually identical values after both four weeks and 15 months. Plasma dopamine was much less affected by exercise and showed only a weak tendency towards higher values during work. While no significant changes were observed after four weeks of treatment, there was a significant 10 to 12 fold increase of dopamine over the control values after 15 months of treatment. At rest plasma dopamine was five and 10 times higher than corresponding noradrenaline and adrenaline levels. The excessive rise of dopamine might have clinical implications: because of the cardiovascular and renal actions of dopamine, high levels should tend towards dampening the negative inotropic effect of beta-receptor blockade and might thus contribute to the increase of cardiac output and decrease of peripheral vascular resistance usually seen with beta-receptor antagonists after longterm treatment compared with acute or short-term administration.

Antihypertensive treatment with adrenergic betareceptor antagonists has been shown to give rise to higher levels of plasma noradrenaline during exercise of different intensities. ${ }^{1-3}$ Conversely, a significant rise of adrenaline has been observed only during near maximal work and was interpreted as reflecting secondary metabolic adjustments to the beta-receptor blockade. ${ }^{245}$ With a few exceptions $^{3}$ these observations were made after acute administration of a beta-receptor antagonist or after short-term treatment. Very little interest has been shown in plasma dopamine. Though dopamine has been the subject of considerable theoretical and clinical interest and research in recent years because of its specific cardiovascular and renal effects, ${ }^{6-8}$ in particular in association with shock, no data are available on the response of Received for publication 4 September 1979 plasma dopamine to long-term beta-receptor blockade.

The purpose of the present study is therefore to define the effect of the cardioselective beta-receptor blocker metoprolol on the response to standardised exercise of plasma noradrenaline, adrenaline, and in particular dopamine after long-term treatment compared with short-term treatment.

\section{Patients}

Seven men aged 25 to 51 (mean 35) years participated in the study after giving their informed consent. Clinical evaluation indicated that all had stage 1 to 2 essential hypertension using criteria described by the WHO (1959). ${ }^{9}$ None suffered from ischaemic heart disease. Blood pressures when measured by the Riva-Rocci cuff method 
ranged between $155 \pm 10 / 101 \pm 4$ (means and standard deviations) $\mathrm{mmHg}$ at rest supine and $236 \pm 30 / 112 \pm 13 \mathrm{mmHg}$ during near-maximal exercise (Table).

\section{Methods}

After initial investigation, treatment was started with a daily dose of $200 \mathrm{mg}$ oral metoprolol and was maintained without any change during the entire observation period. The patients were studied again after a four-week and subsequently a 15month period of treatment under identical conditions and with identical technique as in the initial study. On each occasion, the patients exercised at their individual work loads established during the initial investigation.

On arrival at the laboratory, a polyvinyl catheter was inserted percutaneously via an antecubital vein and the tip positioned in the superior vena cava in order to facilitate blood sampling. After 30 minutes of rest in the supine position, exercise was performed sitting on an electrodynamically braked bicycle ergometer at a rate of $60 \mathrm{rpm}$, starting at 50 watts with a 10 watt increment every minute until a heart rate of approximately 130 was attained. The patients then continued exercising at the same load under steady state conditions for a further 24 minutes. Subsequently, work loads were increased by 25 watt increments every minute and the test concluded by a one-minute work at maximal level. In three patients, however, true maximal work load could not be attained because of an excessive blood pressure response (systolic pressure exceeding $270 \mathrm{mmHg}$ ). This final phase usually lasted four to five minutes. Pulse rates (auscultatory method) and systolic and diastolic blood pressures (Riva-Rocci cuff method) were recorded and blood samples were obtained after 30 minutes of supine lying, during the sixth minute at work load 100 watts, during the 30th minute of submaximal steady state exercise, during near-maximal exercise, and five minutes after work in the sitting posture.

Plasma catecholamines were determined by means of an enzymatic single isotope method ${ }^{10}$ with a coefficient of variation ranging for noradrenaline and adrenaline between 5 and 10 per cent at high and low levels, respectively, and for dopamine between 8 and 14 per cent. ${ }^{11}$ Student's $t$ test for paired samples was used for statistical analysis.

\section{Results}

Heart rate, and systolic and diastolic blood pressures were significantly $(p<0.01)$ reduced at rest and during exercise after four weeks of treatment with metoprolol compared with pretreatment values. No further significant changes were observed after 15 months of continuous treatment; however, there was a clear tendency toward lower diastolic blood pressures during and after exercise (Table).

The exercise-induced increase of plasma noradrenaline tended to be more pronounced after treatment with metoprolol; individual and mean values were virtually identical at four weeks and 15 months (Fig. 1).

The effect on plasma adrenaline was similar; the rise as observed particularly during near-maximal work was of the same order after four weeks and 15 months (Fig. 2).

The levels of plasma dopamine were much less affected by exercise (Fig. 3) and showed only a weak tendency towards higher values during exercise. While no significant changes were observed after four weeks of treatment, there was a significant $(p<0.001) 10$ to 12 fold increase of plasma dopamine over control values after 15 months of treatment with roughly identical levels during all conditions.

Table Heart rates ( $H R$, beats/min), systolic ( $S B P, \mathrm{mmHg}$ ), and diastolic ( $D B P, \mathrm{mmHg}$ ) blood pressures before and after four weeks and 15 months of treatment with metoprolol (means \pm standard deviations, $n=7$ )

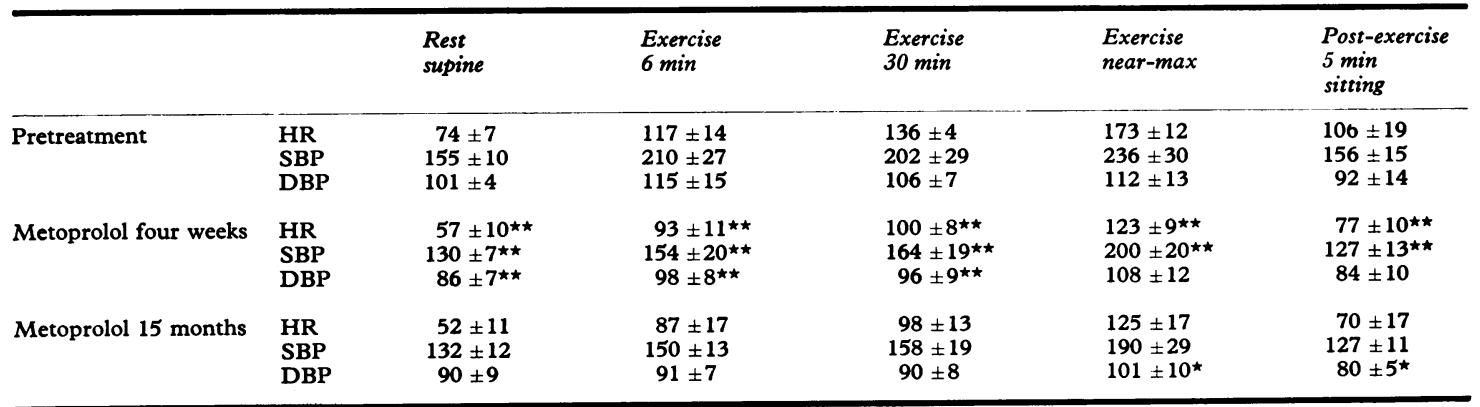

Asterisks denote level of statistical significance of changes from previous examination ${ }^{\star} p<0.05,{ }^{\star} p<0.01$. 
At rest, before exercise, plasma dopamine was five and 10 times higher than corresponding plasma noradrenaline and adrenaline levels (Fig. 4) ( $p<$ 0.001 ) and of the same magnitude as plasma noradrenaline during exercise at 100 watts as well as five minutes after exercise.

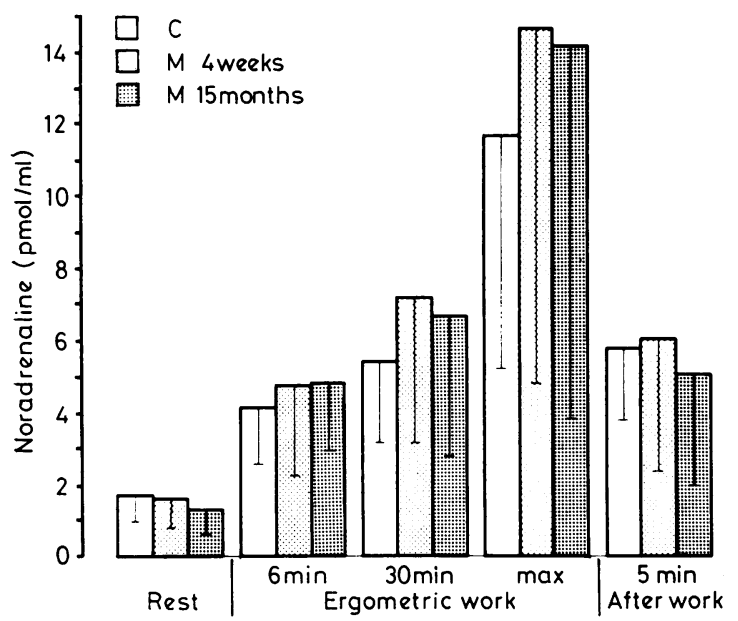

Fig. 1 Plasma noradrenaline at rest supine; during . submaximal and near-maximal work; and five minutes after exercise; before and after a four-week and 15month period of treatment with metoprolol (means and standard deviations, $n=7$ ).

The six-minute exercise corresponds to a work load of 100 watts, the 30-minute exercise to steady state work at $a$ heart rate of approximately 130 beats/minute under pretreatment conditions.

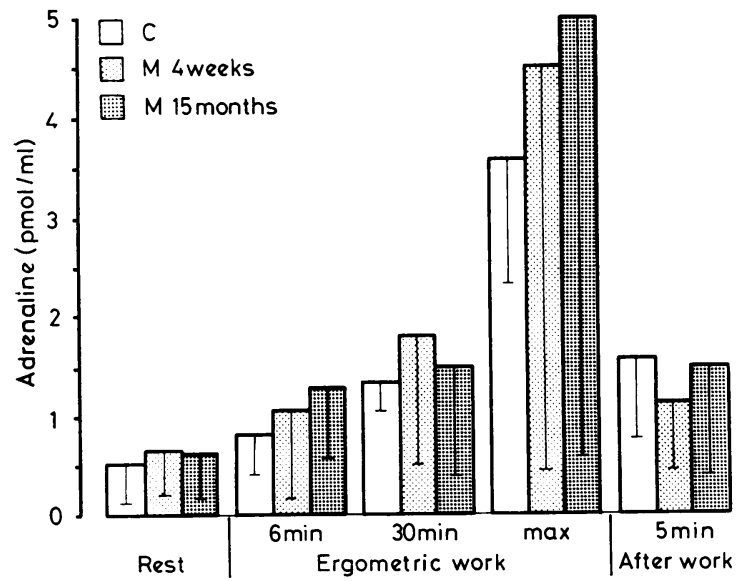

Fig. 2 Plasma adrenaline at rest supine; during submaximal and near-maximal work; and five minutes after exercise; before and after a four-week and 15-month period of treatment with metoprolol. For further details see Fig. 1.

\section{Discussion}

Treatment with the cardioselective adrenoreceptor blocking agent metoprolol resulted in considerably lower blood pressures and pulse rates at rest as well as during and after exercise. Normotension was attained in virtually all patients. The extent of

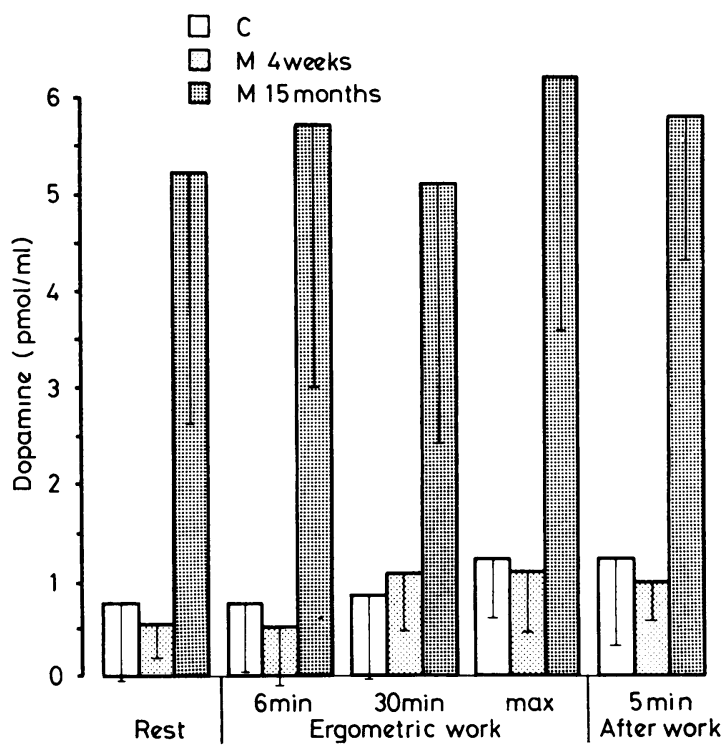

Fig. 3 Plasma dopamine at rest supine; during submaximal and near-maximal work; and five minutes after exercise; before and after a four-week and 15-month period of treatment with metoprolol. For further details see Fig. 1.

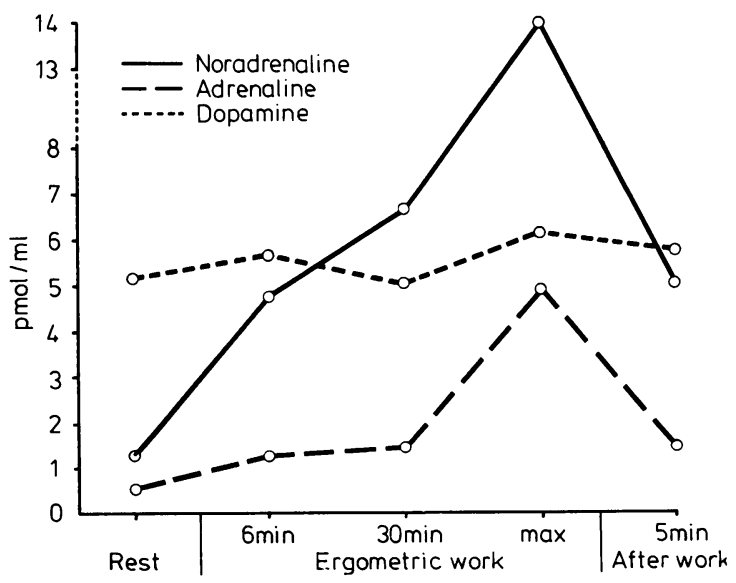

Fig. 4 Means of plasma noradrenaline, adrenaline, and dopamine at rest supine; during submaximal and near-maximal work; and five minutes after exercise; after a 15-month period of treatment with metoprolol. 
pulse rate and systolic blood pressure reduction was almost identical after the four-week and 15-month periods. Only diastolic pressures showed a tendency towards a further slight decrease after 15 months compared with four weeks of treatment.

The fairly constant effect of treatment on the circulation during standardised exercise as evident from the similar pulse rates and blood pressures observed at four weeks and 15 months of treatment is particularly worth noting as it is of great importance when the response of plasma catecholamines to exercise and to treatment of different durations is to be evaluated. ${ }^{5}$

The changes in plasma noradrenaline and adrenaline observed after four weeks of betareceptor blockade in the present series agree with the results reported by other authors. ${ }^{1312}$ The results obtained at four weeks and 15 months, respectively, in our patients indicate that the changes in both plasma noradrenaline and adrenaline induced by beta-receptor blockade remain virtually constant independently of the duration of treatment. Despite unchanged levels of plasma noradrenaline, the diastolic blood pressure tended to be slightly lower after 15 months compared with that at four weeks. This might suggest that levels of circulating noradrenaline do not play a primary or decisive role in the mechanism of the antihypertensive effect exerted by beta-receptor blocking agents. ${ }^{5}$ Even adrenaline does not seem to be of major importance in this respect. The increase of plasma adrenaline after beta-receptor blockade, in particular under conditions of near maximal exercise, reflects a compensatory mechanism aimed at coping with the restricted glycogen breakdown in the working muscle during heavy work. ${ }^{25}$

Plasma dopamine was virtually unchanged after four weeks of metoprolol administration but it showed a considerable rise after 15 months of treatment. The dopamine levels attained are of such an order that haemodynamic effects resulting from the specific properties of dopamine, ${ }^{7}$ are likely to occur $^{13}$ and might have clinical implications. Dopamine has a positive effect on the cardiac contractility resulting in a significant increase in stroke volume and cardiac output. ${ }^{7813}$ Furthermore, dopamine is a potent vasodilator of the renal vascular bed inducing increased perfusion mainly in the renal medulla ${ }^{14}$ and a significant enhancement of sodium excretion. ${ }^{67}$ Because of these specific effects high levels of dopamine should tend towards dampening the negative inotropic effect of chronic beta-receptor blockade. Hence it might contribute to the increase of cardiac output and the decrease of peripheral vascular resistance seen after longterm treatment compared with acute or short-term administration of most beta-receptor blockers, ${ }^{15} 16$ and even alpha-beta-receptor blockers. ${ }^{17}$

Furthermore, the high levels of dopamine may tend to counterbalance the reduced hypothalamic dopaminergic activity shown to occur in hypertensives and to be influenced by the dopaminergic agonist bromocriptine. ${ }^{18}$

It is important to underline that these findings are preliminary; since different beta-receptor blockers may have different effects on plasma catecholamines $^{5}$ they may not apply to all betareceptor antagonists. Thus, the finding of an excessive dopamine increase during chronic adrenergic beta-receptor blockade requires further confirmation and research.

\section{References}

${ }^{1}$ Irving $\mathrm{MH}$, Britton BJ, Wood WG, Padgham C, Carruthers $M$. Effects of $\beta$-adrenergic blockade on plasma catecholamines in exercise. Nature 1974; 248: 531-3.

${ }^{2}$ Galbo H, Holst J, Christensen NJ, Hilsted J. Glucagon and plasma catecholamines during beta-receptor blockade in exercising man. $\mathcal{F}$ Appl Physiol 1976; 40: 855-62.

${ }^{3}$ Hansson B-G. Long-term non-selective and cardioselective beta-receptor blockade in hypertensive patients. Acta Med Scand 1976; suppl 598.

${ }^{4}$ Franz I-W, Lohmann FW, Koch G, Röcker L. Effect of non-selective and cardioselective betareceptor blockade on metabolism during exercise in hypertensive men (in German). Verh Dtsch Ges Inn Med 1978; 84: 813-6.

${ }^{5}$ Franz I-W, Lohmann FW, Koch G. Differential effects of long-term cardioselective and non-selective betareceptor blockade on plasma catecholamines during and after physical exercise. $\mathcal{F}$ Cardiovasc Pharmacol 1980; 2: 35-44.

${ }^{6}$ McDonald RH Jr, Goldberg LI, McNay JL, Tuttle EP Jr. Effect of dopamine in man: augmentation of sodium excretion, glomerular filtration rate and renal plasma flow. $\mathcal{F}$ Clin Invest 1964; 43: 1116-24.

${ }^{7}$ Goldberg LI. Cardiovascular and renal actions of dopamine: potential clinical applications. Pharmacol Rev 1972; 24: 1-29.

${ }^{8}$ Ramdohr B, Biamino G, Schüren KP, Schröder R. Dopamin bei der Behandlung der akuten schweren Herzinsuffizienz. Med Welt 1975; 26: 540-7.

${ }^{9}$ World Health Organization. Prevention and control of arterial hypertension. WHO Tech Rep Ser 1959; 168: 4-9.

${ }^{10} \mathrm{Koch}$ G. Plasma renin activity, epinephrine and norepinephrine at rest and during exercise in young adults and boys (abstract). Scand $\mathcal{F}$ Clin Lab Invest 1977; 37 Suppl 147: 107.

${ }^{11}$ Koch G, Johansson U, Arvidson E. Radioenzymatic determination of epinephrine, norepinephrine and dopamine in $0.1 \mathrm{ml}$ plasma samples. Plasma catecholamine response to submaximal and near maximal exercise. F Clin Chem Clin Biochem 1980; 18: 367-72. 
${ }^{12}$ Grobecker H, Planz G, Wiethod G, et al. Specific and non specific effects of $\beta$-adrenoreceptor blocking drugs in man (in German). Klin Wochenschr 1976; 54: 783-8.

${ }^{13}$ Schmidt HD, Hoppe H, Heidenreich L. Direct effects of dopamine, orciprenaline and norepinephrine on the right and left ventricle of isolated canine hearts. Cardiology 1979; 64: 133-48.

${ }^{14}$ Beckenridge A, Orme M, Dollery CT. The effect of dopamine on renal blood flow in man. Eur $\mathcal{f}$ Clin Pharmacol 1971; 3: 131-6.

${ }^{15}$ Tarazi RC, Dustan HP. Beta adrenergic blockade in hypertension. Practical and theoretical implications of long-term hemodynamic variations. $A m \mathcal{F}$ Cardiol 1972; 29: 633-40.

${ }^{16}$ Frisk-Holmberg M, Juhlin-Dannfeldt A, Jorfeldt L, Aström H. Effect of long-term antihypertensive beta- receptor blocking treatment on haemodynamic and metabolic responses to prolonged exercise in man. Clin Sci Mol Med 1976; 51 : 489-91.

${ }^{17}$ Koch G. Haemodynamic adaptation at rest and during exercise to long-term antihypertensive treatment with combined alpha- and beta-adrenoreceptor blockade by labetalol. Br Heart $\mathcal{F} 1979$; 41 : 192-8.

${ }^{18}$ Kolloch R, Stumpe KO, Higuchi M, Vetter H, Krück F. Raised plasma-prolactin levels in essential hypertension: index of reduced hypothalamic dopaminergic activity? (in German). Klin Wochenschr 1977; 55: 1013-8.

Requests for reprints to Professor G Koch, Department of Physiology, Freie Universität Berlin, Arnimallee 22, D-1 Berlin 33, Germany. 